\title{
DIÁLOGOS DE LUZ: A performance do iluminador e a performatividade da luz
}

DIALOGUESOF LIGHT:The performance of the illuminator and the performativity of light

Natasha Kerolen Leite da Silva ${ }^{1}$ 


\section{Resumo}

Minha fonte de Energia Pesquisante $e^{2}$ parte do meu fazer artístico, como artista-iluminadora-pesquisadora ${ }^{3}$, e essa questão se deu enquanto uma poética pessoal, pela qual fui traçando meu caminho em direção ao processo criativo, focando na busca da visibilidade poética do ato de iluminar. Isto é, a poética elemental é um dispositivo que traduz o meu processo criativo enquanto iluminadora e uma estratégia de trabalho, a qual tratei como uma poética a fim de compreender no fazer artístico uma performatividade na esquematização do ofício. Esta estratégia que se transformou em dispositivo metodológico e didático surgiu quando tracei um paralelo entre os elementos da natureza e a operacionalização no/do processo criativo como performance através dos inúmeros diálogos de luz.

Palavras-chave: Diálogos de luz; visibilidade poética da luz; performance do iluminador; performatividade da luz

\section{Abstract}

My source of research energy is part of my artistic work, as an artist-enlightener-researcher, and this question was given as a personal poetics, by which I was tracing my path towards the creative process, focusing on the search for poetic visibility of the act of enlightening. That is, elemental poetics is a device that translates my creative process as enlightening and a work strategy, which I treated as a poetics in order to understand in the artistic making a performativity in the schematization of the craft. This strategy that became a methodological and didactic device arose when I drew a parallel between the elements of nature and the operationalization in the creative process as a performance through the innumerable dialogues of light.

Keywords: Light dialogues; poetic visibility of light; performance of the illuminator; performativity of light

\footnotetext{
Mestre. Servidora no Teatro Universitário Cláudio Barradas - Universidade Federal do Pará (UFPA) como lluminadora e trabalha como Projetista de Luz, prestando serviços a grupos de Teatro e Dança em Belém. natashakleite1@hotmail.com

${ }^{2}$ Energia Pesquisante é um termo que trago comigo, uma denominação que aplico à força que me impulsiona a criar, é a propulsão do processo criativo, o momento em que jorram as ideias e a mente transborda uma energia de grandeza imaginativa. Não determina início, meio ou fim, mas a renovação de um ciclo de busca pelo conhecimento. É o que posso chamar de aspiração de artista.

${ }^{3}$ Tríade resultante do meu percurso e lugar do qual compartilho esse artigo: artista por ser do palco e uma bailarina em formação; iluminadora a partir das necessidades e do interesse em adentrar os bastidores da cena para compreender a luz no desenho do espaço cênico; e pesquisadora pelo atual momento de poder pesquisar e discutir a importância do meu papel desde a concepção do projeto de luz até a execução da arquitetura cênica.
} 
A luz em si já é uma performance e ao pensar a atividade da luz na construção da imagem cênica, percebo que ocorre uma performance representada no ato de iluminar, em operar aquilo que costura a configuração da imagem em questão, a fim de transformar a luz no suporte de uma mensagem que compõe o todo do espetáculo. Neste sentido de apontar meu processo criativo como um ato performativo - quando palavra e ato coincidem, assumi uma concordância com estudos da performance, e segundo Costa (2015, p 40):

A performance, no senso-comum, está intimamente ligada à ideia de demonstrar/ desempenhar uma habilidade [...]. Tomando a performance como suporte crítico e metáfora do nosso mundo contemporâneo, os Estudos da Performance se posicionaram no cenário acadêmico como uma disciplina em constante diálogo com diversas áreas do conhecimento.

A partir do momento que afirmo a luz como linguagem, compreendo o fazer artístico do/a iluminador/a como performance e os estudos de Schechner (2003) que foram discutidos por Costa me sinalizam o caminho a percorrer:

É importante salientar que Schechner não está afirmando que tudo é performan$c e$, mas sim que tudo pode ser visto como se fosse performance. Pois "qualquer comportamento, evento, ação ou coisa pode ser estudado como se fosse performance e analisado em termos de ação, comportamento, exibição" (Schechner, 2003, p. 39). Richard Schechner constrói uma categoria, uma lente de análise, que pode se voltar para qualquer comportamento humano e até mesmo não humano, e analisá-lo como se fosse performance, mesmo que os sujeitos executantes do comportamento não a definam como tal. [...] Com isso, destacamos que a performance tem que ter alguma intencionalidade, o "mostrar-se fazendo" não pode ser desvinculado da ideia de performance. (Costa, 2015, p. 43-44)

Desde que aproximei as lentes de estudo da performance com a operacionalização, sempre que faço luz, me ponho no papel de realizadora de uma prática performática.

Ao iluminar, coloco à tona uma preocupação nas trocas e no jogo com o corpo atuante, quando organizo minhas ações intencionalmente para atrair o olhar para a cena e procuro ir além dessa experiência visual, busco torná-la uma porta aberta para vivências sensoriais, alterando o estado de corpo do ator e do espectador pela sugestividade da iluminação.

Acredito que a performance se dá a partir do momento em que o/a artista retoma um "comportamento restaurado" ao atuar como mediador de uma lente de observação do espectador, ou seja, operando luz durante a cena ou espetáculo, mediante ao público. A prática desde a concepção do projeto de luz, a criação do desenho ou mapa, a investigação de como retratar a cena e sensibilizar o observador, já é um ato performativo, mostrando que a luz é capaz de dialogar com tudo e que cabe ao artista-iluminador-pesquisador a produção dessas novas percepções, como Braccialli (2015, p. 189-190) justifica:

$\mathrm{O}$ interesse em algumas criações passou a ser a pesquisa de alternativas para que os elementos que compõem a materialidade da cena - como luz, som, objetos etc. - não sejam apenas suportes para a fábula. Pretende-se criar a possibilidade 
do espectador se sentir afetado ${ }^{4}$ pela variação de luz, som, deslocamentos de objetos, enfim, por elementos da espetacularidade que não necessitam de nenhuma referência externa à própria relação palco-plateia.

Ao aproximar o fazer artístico de iluminação à noção de performance, busco relativizar este ofício de criação, e trazer a possibilidade de exemplificar a pesquisa pessoal desse/dessa profissional.

Por outro lado, devo lembrar que a performance ocorre no momento de operação, pois como iluminadora eu aposto na mobilidade da luz, um fenômeno que precisa ter uma escrita, visto que o seu poder de ilusão é instrumento de animação expressiva, portadora de tão referida comunicação visiva, da qual fala Ítalo Calvino; e se concebida com dedicação e responsabilidade no processo de criação, na sua perform-atividade a luz tende a engrandecer a plasticidade esperada na imagem cênica; a mesma imagem que chega como multiplicadora de significados que estão subjetivamente vinculadas à performance, pois independentemente da proposta que o/a operador/a de luz tenha a priori, o movimento desse jogo de imagens etéreas afirma-se na linguagem. Afinal, nossa expectativa é ter a surpresa por algo que nos captura o olhar, nos tocando de forma sutil e liberando sensações a partir do contato visual.

É por essa experiência que considero meus atos como performativos, pela reiteração, no fato de reconfigurar todo o conhecimento que adquiro a cada experiência. A performance se concretiza no ato de iluminar, mas a bagagem de conhecimento e a subjetividade servem-me de embasamento para novas perform-atividades. Como Costa (2015, p 42) mostra que:

[...] nada é completamente novo, nem completamente repetido, mas os atos humanos revelam sempre um "re", de reescrever, reiterar, refigurar. A performatividade antecede o indivíduo, pois os atos ou comportamentos a serem reiterados já existem, antecedem o ente, mas a performance só pode ser executada pelo próprio indivíduo, pois é o mesmo que vai, através de sua subjetividade, reelaborar a performatividade e atualizá-la por meio da sua performance. Com isso, nossa existência não está amarrada à mera repetição de comportamentos, mas nos desvela um eterno movimento entre aprendizado, ao conhecer o comportamento ou os atos, e criatividade, ao ressignificá-los.

Essa é a grande virtude de quem cria luz para cena, saber ler e escrever com a técnica, a sensibilidade e a criatividade. Por isso a iluminação deve acompanhar de perto o processo de criação do todo espetacular, estando inserida nele sendo um possível estímulo e não somente um complemento. Segundo Brandi (2015), a pesquisa de todas as linguagens faz parte do teatro performativo contemporâneo, principalmente a de luz, como justifica a seguir:

Os conceitos de teatro pós-dramático e teatro performativo têm muitos aspectos em comum, especialmente no que diz respeito ao questionamento do poder centralizador do texto e à elevação de outras linguagens artísticas ao plano do texto, assumindo sua importância na construção da trama e da criação colaborativa. A relação do espectador com a trama, a permeabilidade das disciplinas e a multidisciplinaridade em cena são destacadas em ambos os casos. O que é realmente incompreensível, no entanto, é o fato de a iluminação não ter sido citada

${ }^{4}$ O termo "afetado" foi utilizado pelo autor no sentido da variação de sensações a partir da alteração de percepção de um elemento cênico para outro. 
como exemplo de linguagem na definição de qualquer desses conceitos de teatro contemporâneo. A luz como possibilidade autônoma de criação e ação narrativa, totalmente permeável ao conceito de teatro performativo, ainda não foi cogitada. (Brandi, p. 54-55)

Compreendo que pode ser arriscado trabalhar conceitos diferentes, mesmo que a raiz da palavra seja "perform" é preciso ter muita cautela e reconhecer o risco, porém não sou a única que tenta, por isso me respaldo ainda em Brandi (2015, p. 54-55):

[...] Josette Féral, crítica, teórica e professora, aproxima os conceitos da performance e da performatividade e os carrega para o que denomina teatro performativo. Segundo ela, o teatro se beneficiou das aquisições da performance, que transformam o ator em performer, o intérprete em persona e o texto em ação. Esses elementos caracterizam o teatro performativo. O estar no lugar do ser. [...] Se pensarmos a luz como possibilidade narrativa subjetiva, que conduz uma ação performática para se redefinir através da percepção do espectador, estamos falando de questões de imaginação e relação desse espectador com a cena. Se a linguagem autônoma da luz para a criação performativa ainda não foi observada por críticos, diretores, teóricos e pensadores de teatro, acredito que já é tempo de sê-lo.

Acredito também que já seja tempo de observar a dimensão performativa da luz e com o raciocínio que traduz meu trajeto criativo, nasceu um dispositivo metodológico ${ }^{5}$ que é um paralelo entre a quintessência dos elementos ${ }^{6}$ e a obra Seis Propostas para o Próximo Milênio de Calvino (1990) - na qual o autor usa valores literários, os quais pretendo transpor no processo criativo: leveza, rapidez, exatidão, visibilidade, multiplicidade e consistência ${ }^{7}$ - eis então a Poética Elemental.

\section{A poética elemental na criação em iluminação cênica}

Bebi na fonte de Bachelard (2008) e Rangel (2015) para trazer a minha poética de construção nessa linguagem cênica, através do pensar por imagens. E trago junto a este apanhado as muitas contribuições de pesquisas sobre design cênico, estudo das cores, alfabetismo e percepção visual, evoco também estudos da literatura nos quais vejo competência no assunto sobre a visão, o olhar, imagem, etc.

Me coloquei na pesquisa como artista que se dedica na concepção de cenas, na idealização das imagens no palco e da visibilidade que aplico no produto a ser visto pelo espectador. Desse modo, o termo Diálogos de Luz serve para estabelecer a conversa que realizo. E a intenção de apontar uma poética para a iluminação cênica partiu do princípio de que a poética legítima é uma arte, conforme Pareyson (2001, p.15-16) explica

\footnotetext{
${ }^{5} \mathrm{O}$ dispositivo metodológico ao qual me refiro é a Poética Elemental, que surgiu por meio de exercícios de reflexão acerca do objeto de pesquisa que é a luz, e resolvo chama-lo assim pois trata de um "passo-a-passo" que ilustra o meu processo criativo, podendo ser ampliado e utilizado também como ferramenta didática no ensino de iluminação cênica.

${ }^{6}$ A quintessência dos elementos é uma referência ao Cosmo e representada num elemento - o quinto elemento que é o éter. A quintessência simboliza a energia pura constituída de todos os outros quatro elementos da natureza. A quintessência é uma forma de se referir a este universo de poder e energia que está em tudo, e nesta pesquisa faz parte do arsenal reflexivo.

${ }^{7}$ Sendo este último valor, a consistência, parte da obra de Calvino que permaneceu inacabada devido a sua morte precoce, e de certa forma como o número de propostas por ele escritas coincidiu em cinco, pude relativizar com os cinco elementos para fundamentar a poética elemental.
} 
[...] uma poética é um determinado gosto convertido em programa de arte, onde por gosto se entende toda a espiritualidade de uma época ou de uma pessoa tornada expectativa de arte; a poética, de per si, auspicia, mas não promove o advento da arte, porque fazer dela o sustentáculo e a norma de sua própria atividade depende do artista. [...] uma poética é eficaz somente se adere à espiritualidade do artista e traduz seu gosto em termos normativos e operativos, o que explica como uma poética está ligada ao seu tempo, pois somente se realiza aquela aderência e, por isso, se opera aquela eficácia. [...]. Do ponto de vista estético, todas as poéticas são igualmente legítimas [...] o essencial é que seja arte. [Grifo nosso].

Já no sentido de construir este dispositivo de pensamento como uma metáfora de raciocínio, a qual testei como caminho para a criação em iluminação cênica, o contorno do objeto/fenômeno luz foi conduzido por uma ordem pessoal dos cinco elementos (éter, terra, água, fogo e ar), culminando no objetivo da visibilidade, representado pelo elemento fogo, que em si representa esta função primária e essencial, mas não única, referente a iluminação.

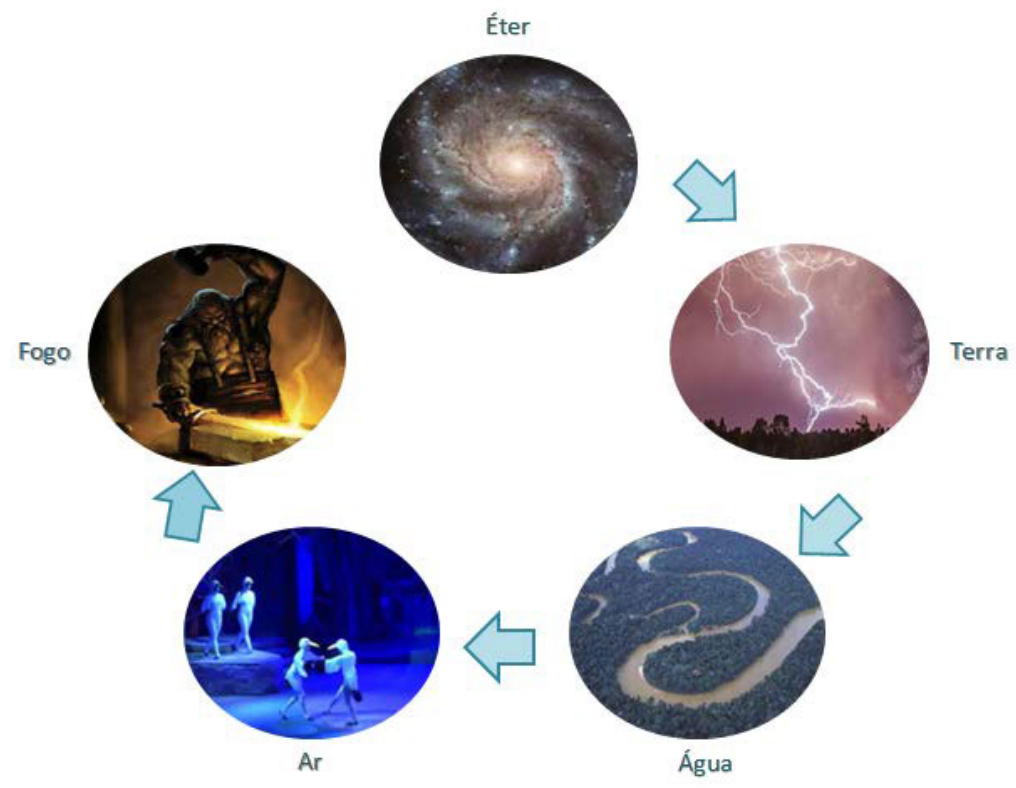

Imagem: Imagens-força (ordem segundo a Poética Elemental)

Fonte: Elaborada pela artista-iluminadora-pesquisadora, a partir de imagens disponíveis na internet que foram indutoras ao pensamento.

A imagem acima foi montada a partir das imagens-força ${ }^{8}$ de cada elemento. Com essa iniciativa, ficou muito mais claro o caminho que eu percorria durante o processo criativo. Associei cada elemento a uma das propostas escritas por Ítalo Calvino, e estabeleci uma ordem que finaliza no elemento fogo e visibilidade, no qual percebo que acontece o desfecho que necessito para o meu desejado diálogo de luz.

Calvino traz a poesia como carro chefe de sua discussão e sua poética nas conferências destaca os valores pertinentes à escrita, logo, compreendi que a iluminação cênica é a minha forma de escrita artística (linguagem). Ganhei então, uma forma de metalinguagem, ou melhor, uma metáfora que explica poeticamente a minha linha

${ }^{8}$ Imagem-força foi um dos termos usado em exercício de análise do objeto de pesquisa ainda durante o percurso de mestrado, observando a relação de cada imagem e os significados somados ao movimento criador da poética, elaborando instrumentos valiosos de percepção 
de pensamento enquanto ideal de arte e que transporta a minha espiritualidade de artista traduzindo também o meu gosto e organização em termos operativos. Esse fator foi de imenso valor, visto que a compreensão da minha "forma de fazer" pode somar aos processos didáticos de e à forja da escrita de luz.

\section{O éter e a leveza da volatilidade}

Existem inúmeras teorias que falam do elemento Éter, procuro não contaminar a minha lente pela generalidade dessas teorias, mas busco nelas alguns pontos que justifiquem a minha escolha por começar neste elemento que representa a quintessência da natureza.

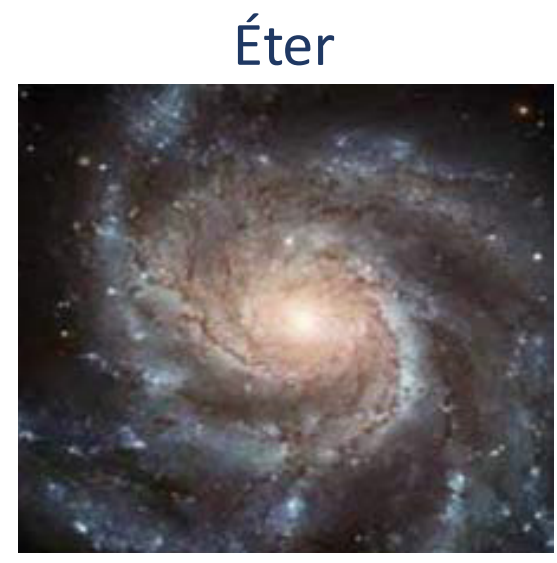

Acho importante lembrar que no momento em que aponto a volatilidade do éter, quero me referir ao movimento que ele me traz, e também ao meio pelo qual se realiza a concretização da minha linguagem - que é a luz.

Sendo a luz é dotada de matéria, mesmo que se propague em ondas (visto que as teorias físicas afirmam que a luz seja de natureza ondulatória), é no éter que se propaga, por isso outras linhas de pensamento afirmam que o éter é o elemento que constitui o universo. Dentro desse entendimento, escolhi a imagem do cosmos que agrega todos os outros elementos em si e representado pelo espaço que é capaz de transmitir luz, constituindo-se dela também. E a partir da mesma imagem, relativizei o elemento como o meu modo de ver o mundo, um ângulo de sonho, digressões e melancolia que se faz leve e silenciosa no vácuo em chiaroscuros ${ }^{9}$, que separam o meu olhar do objeto.

Seria o elemento éter a essência pulverulenta e consistente ao mesmo tempo, aspecto constituinte de um todo trazendo nuances de estabilidade e instabilidade na representação de leveza da luminescência da cena. Me remeti a verbos de ação ${ }^{10}$ no movimento de criação e a partir do devaneio, encontro como funções relacionadas ao éter, as capacidades de: acentuar, colorir, modificar o peso, saltar e comunicar a fim de sensibilizar o espectador que recebe a imagem cênica do palco. Forjaz (2015) consegue me remeter ao movimento do éter na descrição do objetivo de ter a luz como linguagem:

\footnotetext{
${ }^{9}$ Técnica de claro-escuros criado por Leonardo Da Vinci, no Renascentismo. A técnica evidencia os índices de luminosidade, o que reforça a sugestão de volume dos corpos.

${ }^{10} O$ termo "verbos de ação" utilizado aqui, tem relação com cada elemento e os aspectos qualitativos que o movimento deles me estimula no ato criador.
} 
[...] a junção de todas as artes no palco leva a encenação teatral a ser pensada como uma linguagem que articula um conjunto de linguagens. [...] A criação do espetáculo deve ser então resultado de uma síntese conceitual que coordena os vários elementos da cena em movimento. [...] por meio de uma reorganização dos elementos visuais: linhas, formas, volumes e cores ganham flexibilidade através do movimento da luz em sua relação com a matéria e os olhos. (Forjaz, 2015, p. 129)

Pensando deste modo, encontrei na poesia de Calvino um veículo fundamental para sugestões emotivas da arte, é o tempo de "passagem da palavra à imaginação visiva" (1988, p. 103), neste ponto eu trato do movimento de transformação das coisas e da criação do novo que ocorre no starting. Quando entendi a leveza da escrita à qual Calvino se referia como proposta, trouxe essa qualidade leve ao movimento volátil do éter, como o princípio de diálogo do pensamento que tende a ser sonho e depois começa a ganhar corpo.

O elemento éter representa o princípio do meu raciocínio, o momento de captura das ideias, o início da rotina de criação nos pensamentos. São insights da imaginação que viabilizam uma proposta de cena, é aquele devaneio que aparece numa chuva de ideias. Normalmente imagino o resultado como uma espécie de visão da luz cênica que vem por meio de um sonho, pois acredito que a minha forma de concepção dessa arte é primeiramente onírica, para que meu olhar possa desvelar sensações conseguintes.

É o vislumbre imagético que antecede a construção da minha escrita em cena. Logo, meu éter é o momento em que minhas ideias estão nascendo, o estágio embrionário do projeto de luz cênica, e sua característica é a leveza dessa possibilidade de ser e não ser ao mesmo tempo, um universo de respostas, ou melhor, o "universo cênico ideal" que tenha a iluminação como uma das principais vias de sensações para o espectador.

Não é algo estático, é tridimensional e volumétrico. É uma pesquisa ao conteúdo técnico incorporado que foi construído pelas vivências anteriores para a seleção de uma memória a fim de reconfigurar o que pode representar a nova proposta. A partir disso a construção do processo é que tende a pesar para o próximo diálogo, pois a terra irá receber toda a potência dessa energia pesquisante. Logo, o movimento de leveza do éter tende a descer para a exatidão, na qual busco firmar as imagens que flutuam subjetivamente para que sejam traduzidas e então concretizadas.

\section{A terra e a exatidão na potência de energia pesquisante}

\section{Terra}

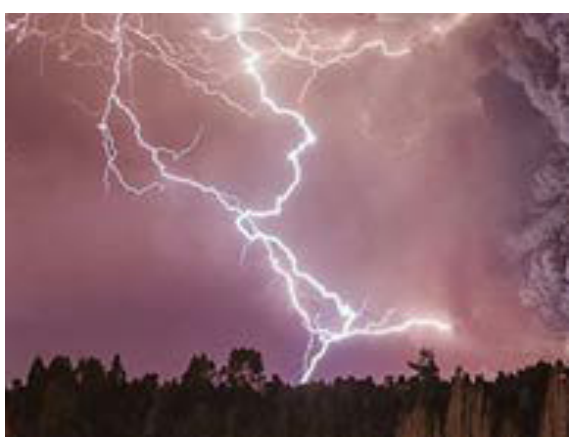


A imagem força que me guiou nesse diálogo com o elemento terra foi a do princípio de aterramento que tem relação com o escape de uma energia potente capaz de descarregar sobre a terra toda sua força, com a exatidão de um raio e a luminosidade que desce até o chão.

Ainda fazendo referência a este fenômeno natural, entendi o elemento terra como o solo, uma base que me sustentou em oposição aos devaneios, apontando o movimento de Exatidão que segundo Calvino (2009), é descrito pela formação de ideias visuais nítidas e uma linguagem precisa, mas capaz de traduzir o imaginário.

Em uma dinâmica de aterramento, foco na terra com sua solidez de base fértil, assim compreendo a força cognitiva e sensível à tensão e intensidade da iluminação no meu trabalho, logo, potencializo a luz como escrita fundamentada. E conversando com a obra chamada Trajeto Criativo de Rangel (2015), trabalhei em cima de verbos de ação elegidos pela qualidade de movimento relacionado a terra, como: aterrar, energizar, calcular, atrair e vazar.

É a etapa da definição do projeto de luz, quando o conhecimento empírico, teórico e prático é posto em prova, e a idealização passa a tomar forma, num rabisco, em notas, num desenho. Ponto de transpor técnicas capazes de traduzir o imaginado, buscando uma linguagem precisa de cálculo e de estratégias, com a segurança de formalizar a comunicação visual. Surge então, uma espécie de registro, algumas anotações que definem o trajeto de uma futura montagem ou um "mapa de luz ".11

O movimento terra se dá com as anotações que faço a partir do meu primeiro contato com o processo de criação. Tento visualizar a partir das informações que organizam o contexto da cena, uma geral ou foco que será necessário para determinado recorte importante, a ênfase que preciso dar a partir da luz. O elemento terra é representado pelas proposições que faço depois de contemplar a cena mentalmente, ou depois de uma conversa, durante um ensaio ou a partir de um roteiro que ainda não é definitivo; e esse molde caracteriza o próximo movimento, o diálogo da luz com a água e a proposta de rapidez da formatação.

\section{A água e a rapidez na sua formatação em corrente}

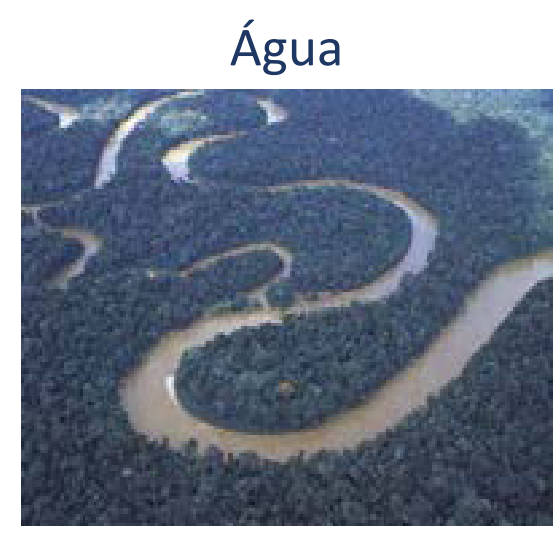

A Rapidez veio a mim representada pela imagem de braços de rio, a água que percorre esse caminho me afeta diretamente na questão do olhar que é arrastado para a margem de uma corrente ágil e formatadora.

\footnotetext{
${ }^{11}$ Mapa de luz, também conhecido como planta baixa de luz, é o nome dado ao projeto técnico desenhado para iluminação de um espetáculo e que contém especificações de como e onde posicionar ou distribuir as fontes de luz, os tipos de refletores e ligações adequadas.
} 
Nesse movimento, o exercício de pensar por imagens é poético e revelador; e quando a imagem é o resultado almejado, Calvino (2009, p. 106-108) me sustenta na prática de desenvolver as potências daquilo que observo, quando diz:

A partir do momento em que a imagem adquire uma certa nitidez em minha mente, ponho-me a desenvolvê-la numa história, ou melhor, são as próprias imagens que desenvolvem suas potencialidades implícitas, o conto que trazem dentro de si (p. 106). Em torno de cada imagem escondem-se outras, forma-se um campo de analogias, simetrias e contraposições. Na organização desse material, que não é apenas visivo mas igualmente conceitual, chega o momento em que intervém minha intenção de ordenar e dar um sentido ao desenrolar da história. [...]. Ela é que irá guiar a narrativa [...] serve de estímulo à fantasia figurativa (p. 107). [...]. Seja como for, as soluções visuais continuam a ser determinantes, e vez por outra chegam inesperadamente a decidir situações que nem as conjecturas do pensamento nem os recursos da linguagem conseguiriam resolver (p. 108).

Ítalo Calvino (2009) consegue desvendar a rapidez na escrita poética pela velocidade narrativa, uma necessidade para a lógica, que dará a ideia de continuidade em favor do ritmo, o que segundo ele, facilita as ligações sem dispersar a atenção, mantendo o fluxo, a corrente, o tempo, por isso afirma:

A arte [...] está no saber encadear uma história a outra, interrompendo-a no momento exato: duas operações sobre a continuidade e a descontinuidade do tempo. É um segredo de ritmo, uma forma de capturar o tempo que podemos reconhecer desde as suas origens: na poesia épica por causa da métrica do verso, na narração em prosa pelas diversas maneiras de manter aceso o desejo de se ouvir o resto. (Calvino, 2009, p. 53).

A intensidade dos corpos se alteram debaixo da energia que ultrapassa as ligações elétricas e carcaças de refletores; o aquecer das lâmpadas faz fluir as ações no palco, essa alteração emocional é como uma purificação do estado de corpo. Penso assim porque a água é um elemento de purificação segundo alguns mitos, e quando faço a relação da corrente de água com a corrente elétrica que abastece meus equipamentos, percebo que a fruição da energia iluminante faz o corpo no palco dilatar e quando purificado de tudo aquilo que não pertence a cena, a sua arte transborda.

A capacidade que a água tem de formatar e ser moldada em outras formas tem uma relação estética direta com a luz através da minha lente de observação, penso que seus braços de rio percorrem um caminho até transbordar, a água tem o objetivo de vazar e de ligar fontes pequenas de um simples olho d'água por correntes que a levam a desembocar nos rios e mares, até transbordar em oceanos, e num movimento de liberdade vai desenhando suas margens.

Da mesma forma, com a luz eu posso inundar um espaço, consigo despir diversas formas num palco, e com movimentos de transição ora lenta, ora rápida passo a comunicar a intenção da imagem formada. A percepção do espectador, o calor das luzes e o desenho dos feixes e raios luminosos são respostas para o jogo de operação da realidade da cena.

As formatações às quais me refiro, são de força sugestiva para melhor relativizar o tempo dentro da obra, seja na velocidade física ou mental. O/a artista da luz deve ler e compreender a imagem cênica e com a técnica, a sensibilidade e a criati- 
vidade, compondo a plasticidade da proposta para a razão do espetáculo. Quando me refiro ao diálogo da luz com o movimento água e a proposta de Calvino para rapidez, estou focando na formatação, a ligação entre cenas, o que operacionalmente trata de transição.

Calvino trabalhou a proposta de rapidez segundo a intenção de ordenar e dar sentido a uma narrativa. Como poeta cuja escrita é de luz, o/a iluminador/a soluciona visualmente o andamento das cenas, no encadear da história para que a métrica, ou melhor, o ritmo narrativo do espetáculo não se perca. Tem relação direta com dramaticidade (função expressiva), que a luz pode alcançar no tempo e espaço de realização.

A dilatação de um movimento, o estado alterado do corpo e a troca de forças na cena são formas de perceber o movimento água da poética elemental. É intensidade e constância, fluxo dirigido ao espectador por meio de uma maneira de narrar. E o autor Camargo (2015, p 113) diz que a vitalidade da luz tem importância para a manutenção do fluxo:

O entendimento da iluminação como recurso externo e dotado de am $\neg$ plos poderes de manipulação sobre a cena tem difundido a ideia de que a luz constitui um meio capaz de aproximar, distanciar, ilustrar, recortar, intensificar, entre outras tantas coisas que se pode fazer com ela. No entanto, essa é a luz que a iluminação cênica produz, e não a iluminação da luz propriamente dita, ou seja, da luz que está intrinsecamente ligada à cena, com cuja vitalidade dialoga incessantemente, no mesmo fluxo de espaço-tempo.

Nesta etapa da poética exponho a vitalidade que Camargo (2015, p 114) prediz com a afirmação de que "a função primária da luz reside na interação física com as coisas que ilumina e o que resulta disso, capaz de transcender os olhos e alcançar o inconsciente".

Experimentando esse fluxo que ganha presença e ritmo com o movimento diferenciado dos raios luminosos, percebo a luminosidade que percorre e depois atravessa os espaços vazios entre corpo(s) e acaba vazando num banho de luz. Esse tipo de formatação é um exemplo de pensar por imagens, a imagem que me inspirou em seus braços de rios pode ser rememorada nesta sugestiva descrição com este corpo que permite caminhos por onde os feixes de luz escapem, me conscientizando de que a luminosidade forme as margens e modele na cena.

No movimento água, já encaro a nitidez do trabalho, dos recursos e das potencialidades nesse discurso por imagens. Por meio de ensaios e do contato com a luz, faço a ligação do fluxo das ideias, ordenando e dando sentido de continuidade em favor da cena, busco nessas experimentações encadear as ações e afinar a proposta de luz ao processo criativo do todo espetacular.

\section{O elemento ar e a multiplicidade no espaço de diálogo}

Este elemento representa aos meus olhos a expansão do conhecimento, o constante processo de reconfiguração das coisas, dos ideais e dos moldes encontrados num trajeto criativo. É a interligação dos saberes que prioriza o diálogo, e na arte de iluminar é uma forma de realização do ato de tornar algo visível pela linguagem poética que desvela a intenção. 


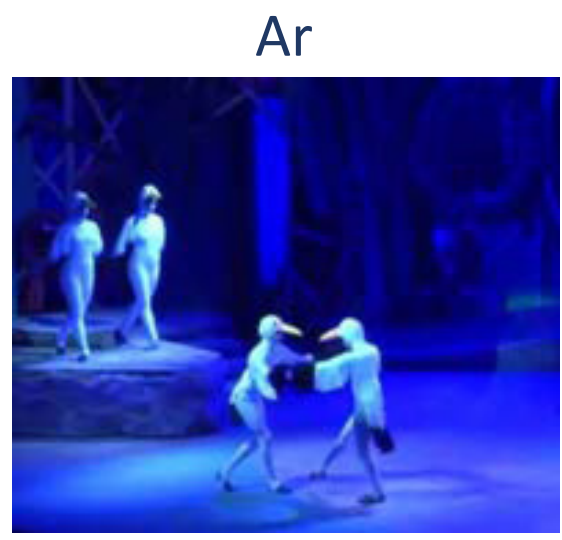

Sabendo que na iluminação existe um escritor/poeta, encaro essa possibilidade de multiplicar os detalhes da cena pelo diálogo da luz, visto que a primeira visão do espectador é a ótica de quem ilumina, mas não significa dizer que se detenha a ela, pois será apenas a primeira proposta de realidade que lhe afetará a percepção; é essa lente do/a iluminador/a que denomino de self de autor, podendo assim ter vários desdobramentos e interpretações.

Rangel (2005, p. 9-11) me inspira na obra CasaTempo, sobre a questão do olhar do artista - no meu caso o olhar de duas pessoas da tríade - a artista-iluminadora:

todo ver é sempre sonhar

todo sonhar é sempre ver

O universo que me interessa é a própria essência do que é arte: a capacidade do artista em reinventar o mundo.

O exercício de criação do artista, segundo Rangel, é a partir da visualização de imagens que revelam sonhos e suas reinvenções. Assim, ressalto como se pode imaginar o produto final a partir do desenho de realidade que a luz tenta alcançar, seria a sua reinvenção de mundo, por uma lente iluminada e iluminante - uma escrita que pode render muitas leituras ao público, mas antes disso rende diversas leituras dentro do próprio contexto da cena e diante dos coparticipantes e colaboradores, devido a sua multiplicidade.

Cibele Forjaz (2015) aponta em seu trabalho uma função da luz como sendo "um texto capaz", logo, me aproprio desse paralelo para reafirmar a iluminação como a escrita cuja linguagem é especificamente iluminante, onde o/a autor/a cria uma poética pessoal que seguirá um roteiro de atuação juntamente com todo contexto cênico. Segundo a autora Forjaz (2015, p 132):

As lâmpadas não falam por si. Se não houver por parte do iluminador um conhecimento profundo do texto, do processo de construção da cena e articulação com as diversas linguagens de que é composto o espetáculo, segundo os conceitos da encenação, as lâmpadas de um teatro valem tanto quanto a lâmpada de uma sala de estar, ou de uma vitrine de roupas. O roteiro da iluminação cênica é o texto da luz. E como tal precisa ter consciência do seu poder de articulação. É preciso fazer a língua falar com sentido para ser de fato linguagem. Se os profissionais da cena, entre eles os encenadores e os iluminadores, não souberem pensar a luz como linguagem estrutural e estruturante da cena contemporânea, ela não o será, assim como não o foi quando a luz elétrica surgiu, simplesmente porque 
“deu a luz”. Daí a importância de pensar o processo de transformação da luz em linguagem na história do teatro para poder atualizá-lo aqui e agora [grifo nosso].

É esse roteiro que faz a articulação do espetáculo e a transição das cenas com as demais linguagens, mas para isso é necessário saber escrever por esta linguagem, não basta dominá-la, é preciso conhecer a sua capacidade e daí entendo a multiplicidade dos sonhos, que defende Sônia Rangel (2015), como a visualização de imagens para aproximá-las dos resultados. Lembrando que, no movimento anterior, com o elemento água, já foi iniciado o diálogo com a experimentação de luz, e no movimento ar cabe pensar a execução da mesma para que seja capaz de estruturar a imagem cênica definida pelo processo de criação.

Nesse sentido, a multiplicidade pela minha ótica seria uma rede de ligações que parte da comunicação visiva, uma espécie de lente caleidoscópica acrescentando os detalhes percebidos e transformando-os em conteúdo imagético para outras combinações futuras na memória, ao entrar em contato com figurinos, cenários e qualquer outra escrita que compõe o todo do espetáculo.

A inspiração e a criatividade trazem o movimento ar na minha pesquisa, pois elas podem ser recombinadas infinitamente através da leitura imaginativa e das ideias de concretização visual conjuntamente. Alguns verbos de ação são atrelados a esse movimento: criar, renovar e reagir a partir de outras confabulações. Acredito que posso representar o movimento ar pelo sistema combinatório de um caleidoscópio, devido a possibilidade de reformular inúmeras imagens a partir das que já foram pré-visualizadas.

Nesse emergir de novas imagens a cada combinação de efeitos, surge o verdadeiro ato de reinventar o mundo por uma ótica singular, como Sônia Rangel (2015) aponta na capacidade de criação do autor de uma obra, que no caso da iluminação acaba sendo particular de cada iluminador/a, mas que pode percorrer a mesma direção que é de provocar o espectador, de sugerir emoções e buscar na memória daquele que atua, ou de quem observa, muitas outras formas, recortes, cores e imagens com sentido e modos de ler a obra.

No elemento ar, caracterizo a expansão do conhecimento no processo de reconfiguração das cenas devido a relação que faço com a proposta de multiplicidade de Calvino. É a deliberação da escrita poética que no momento da ação torna algo visível além dos seus olhos, pois toca a sensibilidade e provoca desdobramentos e interpretações variadas.

Já nessas interpretações, pode-se perceber o ressignificado de cada desdobramento como multiplicidade do diálogo, e segundo Camargo (2015, p 114), trata-se de uma luz também atuante na cena:

Estaríamos falando, pois, de uma luz que não permitiria somente ver e entender o significado proposto por intermédio dela, mas capaz de provocar a percepção, de despertar sentimentos, de fruir mais profunda $\neg$ mente a experiência cênica. De uma luz atuando em concomitância com a cena; que não se dá a ver por desenhos ou formas criadas a priori, mas por átimos e impermanências que iluminam o material e o imaterial, o tangível e o intangível.

Para compreender a multiplicidade é preciso reconhecer que o/a criador/a de luz põe a prova e ensaia sua proposta de realidade cênica e tudo que envolve o con- 
texto do processo, testando sua lente e dialogando com o que Gill Camargo (2015. p 107) diz necessário para "entender a luz como uma fonte de energia que afeta a cena teatral e é afetada por ela".

Não existe a possibilidade de afirmar um predomínio de linguagem nas trocas durante as cenas, são incessantes as variáveis e independentes entre si, trabalhando em estado de prontidão para uma resposta poética, a exemplo posso citar os corpos atuantes de um mesmo espetáculo, que podem reagir de acordo com a individualidade de cada um e não necessariamente precisam sentir o mesmo estímulo.

Muitas vezes o/a criador/a da luz articula a musicalidade e a movimentação do corpo para transitar as luzes, fazendo dos raios luminosos a força motriz, ora jogando com os contrastes, ora poetizando o caminho para eles seguirem e assim performarem segundo o diálogo que cabe na preparação, nos ensaios e afinações entre as linguagens.

Ao confiar na sua própria capacidade, o/a artista de luz experimenta, simplesmente multiplica as possibilidades de tocar o espectador com transições que despertam memórias afetivas, lembranças estimuladas pela função expressiva da luz. 0 exemplo desse movimento é a possibilidade de variação do mapa de luz, que não é algo definitivo nem a segurança de um raciocínio fixo.

\section{O fogo e a visibilidade forjada no ofício da iluminação}

O caminho que tracei pelos elementos teve uma costura intencional, uma coerência a partir do meu raciocínio de criação e performances, a fim de ter a função da visibilidade como produto do ato de iluminar e também como subjetivação da poética relacionada à imagem cênica que chega ao espectador.

\section{Fogo}

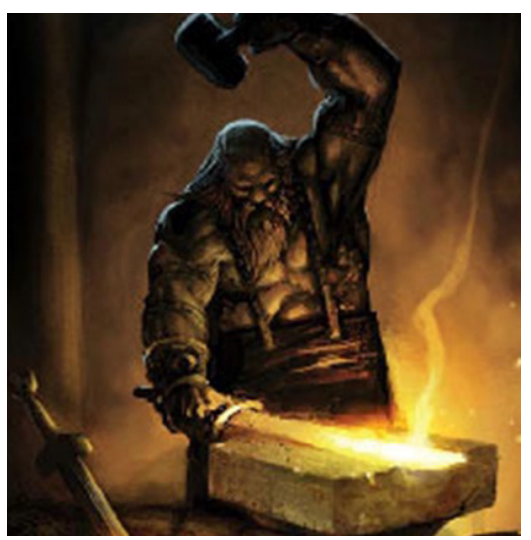

Ao ler a obra de Ítalo Calvino (1990), Seis propostas para o próximo milênio, uma das conferências que mais me prendeu a atenção, foi a Visibilidade que conversa diretamente com o elemento fogo em minha poética.

Ao relacionar tudo que vinha à mente ao pensar em fogo, me reportei a um mito grego, o de Hefesto (ou Hefaístos), deus grego que é considerado o deus do fogo e dos artesãos, devido seu trabalho manual com o ofício dos metais, e em outras versões é também considerado o deus das artes. $O$ interessante da personagem desse mito é que ele não habita o Olimpo, por ter nascido coxo e feio (fora dos padrões de beleza), foi banido da habitação dos deuses e fez sua forja dentro de um vulcão chamado Etna. 
Hefesto era um artífice que produzia objetos artesanais em metal e com a sua sensibilidade criativa repassava a perfeição que não havia em sua aparência física diretamente para a sua arte. As imagens que o representam normalmente são de um homem feio e debruçado numa bigorna forjando armas. É nessa forja que observo o poder do fogo, de transformação e de refinamento.

A visibilidade literal que o fogo proporciona não é a única representatividade deste elemento. Encaro a luz do fogo como o acender do objetivo no ofício de iluminar, na intenção de construir a imagem cênica.

Alguns atravessamentos orientaram meus verbos de ação para este elemento que também têm relação com o meu ofício de investigador/a: queimar, como se queima as possibilidades; cortar aquilo que não soma ao trabalho; refinar o olhar, o trato e a escrita da pesquisa; aquecer a cena com as propostas de trabalho de luz; e finalmente, o meu forjar traduzido na técnica e arte de iluminar, nos projetos e operações - ato finalizador da performance do/a iluminador/a.

Ao apontar à finalização da performance, percebo o processo de tornar translúcida a imagem visível pelo meu trabalho. Estabeleço diversas leituras de mundo, uma espécie de universo ilusório e criativo ou de mundo simbólico, direcionando o olhar do espectador para o impalpável na cena. Calvino (2009, p 101) afirma que:

[...] o poeta deve imaginar visualmente tanto o que seu personagem vê, quanto aquilo que acredita ver, ou que está sonhando, que recorda, ou que vê representado, ou que lhe é contado, assim como deve imaginar o conteúdo visual das metáforas de que se serve precisamente para facilitar essa evocação visiva.

E diz também que a visibilidade se trata da fantasia, do sonho, parte do mecanismo individual ou coletivo que se faz importante no contato com a imagem. É realmente o estabelecer da comunicação visiva como um veículo fundamental. $E$ ainda adverte assim:

Se incluí a Visibilidade em minha lista de valores a preservar foi para advertir que estamos correndo o perigo de perder uma faculdade humana fundamental: a capacidade de pôr em foco visões de olhos fechados, de fazer brotar cores e formas de um alinhamento de caracteres alfabéticos negros sobre uma página branca, de pensar por imagens. (Calvino, 2009, p. 110)

Neste ponto o meu interesse é compreender de outra forma a visibilidade da luz, fazê-la poética da linguagem de um ofício pessoal e conceitual. Partindo do pressuposto de Forjaz (2015, p.128):

No entanto, ainda foi preciso mudar o paradigma do teatro para que a luz deixasse de ser pensada e utilizada unicamente como instrumento da visibilidade ou efeito especial da ciência para arrebatar suspiros. Será necessária uma razão para que deixe de se ofuscar e ser ofuscada pela própria beleza. [...] A iluminação cênica passa a ter com a utilização da eletricidade o poder, através do movimento, de desenvolver uma partitura do que é visível em cena, e como é visível. E, portanto, o poder de se transformar em linguagem. Entretanto, o instrumento da mudança não é a mudança. Nem o pincel e as tintas são a pintura. A iluminação cênica não virou linguagem por causa da utilização da luz elétrica no teatro, embora ela te- 
nha dado a ferramenta necessária para isso, assim como a iluminação não é linguagem a priori, só porque usamos de alta tecnologia na projeção de luzes e imagens. A linguagem é uma possibilidade de articulação, uma potência que depende da necessidade e da prática para se atualizar, assim como o discurso depende do conhecimento da língua e também da necessidade da comunicação que o articula. É por isso que além de falar, o homem necessita compreender a estrutura da fala e as necessidades do discurso. É através desse processo de compreensão e articulação que o som vira língua, a língua vira linguagem, o discurso, obra de arte. [...] o surgimento da arte da encenação, que criou a necessidade e o conceito da luz como verbo do olhar [grifo nosso].

Na reflexão de Forjaz observo o verbo olhar como parte do conceito de luz, significando essa luz como uma potência enquanto linguagem, a possibilidade de articulação na iluminação cênica; potência que se atualiza na prática de artista iluminador, prática que exemplifico com o percurso da poética elemental. Existe um discurso por imagem, que é a imagem cênica completa e por si cheia de significado - esta é a visibilidade poética, pensar por imagens que são desenhadas por raios luminosos, chiaroscuros, focos e gerais coloridas a fim de sensibilizar aquele que observa a cena atentamente para as indicações de minhas transições luminosas, reciclando as múltiplas imagens que se apresentam diante dos olhos e se multiplicam no imaginário do espectador.

Braccialli (2015, p 189) exemplifica meu entendimento assim:

A função da iluminação no teatro é proporcionar percepção visual da cena para o espectador [...]. Quando o espectador assiste a um espetáculo, a cena pode criar em sua imaginação outro mundo diferente daquele ao qual a cena remete em primeiro plano. Mesmo quando não se trata de um universo ficcional fechado, a cena pode sugerir traços de ficções e relações mais ou menos indiretas com uma ideia de realidade.

Braccialli traduz o que eu chamo de movimento ar ainda, e o exercício do movimento fogo na forja se atualiza quando o/a iluminador/a se apropria de toda técnica e empiria para traduzir as cenas; construindo o universo ficcional e lançando mão de equipamentos usuais, seja de tecnologia de ponta ou aqueles que consideramos "gambiarras"12 - nessa fase a visibilidade poética se dá por meio da qualificação de materiais que possam suprir os efeitos desejados - aliando esse conhecimento, o/a iluminador/a se torna o artífice do efeito, cuja sensibilidade da percepção visual se aprende na prática.

O fascinante na forja de iluminação é a capacidade que adquirimos de conhecer e reconfigurar ou ressignificar materiais. É depois desse mergulho que chega o momento de apresentar o produto ao público. É quando obtemos o reconhecimento de uma dedicação ao ofício de fazer da luz uma linguagem de visibilidade poética e esclarecedora.

\footnotetext{
12 "Gambiarra" é um termo utilizado na iluminação cênica para uma ligação elétrica simples, normalmente uma extensão de fio comprido com um ponto de luz que permite o manuseio com facilidade. Pode significar também: ligação improvisada e artesanal, normalmente por falta de materiais; ou circuito de lâmpadas como solução alternativa para decoração.
} 


\section{Black Out (Considerações Finais)}

Sendo a iluminação uma linguagem cuja escrita é potente e o/a iluminador/a um/a criador/a e também responsável pela atualização dessa potência enquanto articulação da cena, a visibilidade poética é a leitura dessa linguagem.

Como escrita, a luz cria um texto capaz de informar visualmente, e a poética elemental pode se tornar um dispositivo metodológico útil para a criação em iluminação cênica que vai permitir os diálogos da luz na cena. Os múltiplos detalhes que o diálogo da luz confere, faz com que o/a artista de luz seja uma das figuras importantes na construção espetacular. Logo, os caminhos da poética elemental compõem um ato performativo do/a iluminador/a enquanto a sua performance se realiza no ato de operar essa luz diante do público, atrás da mesa de luz, nos bastidores, quando sua obra é apresentada ao espectador.

Compreendo a minha necessidade de constantemente recorrer à esta poética, como programa de estudo artístico em iluminação, para poder rever aquilo que faz parte do meu arsenal de conhecimento na área e continuar traçando meu trajeto criativo como artista na forja de luz.

Como faço uso de termos próprios da iluminação cênica ao longo desta escrita, escolhi tratar minhas considerações aqui, temporariamente "finais", como um simples BLACKOUT ${ }^{13}$. Este escurecimento é apenas uma transição da artista-iluminadora-pesquisadora, que vos escreve apaixonadamente a fim de compartilhar a luz que arrebata os olhos e o coração. Reverencio sua persistência nesta leitura.

Enfim, a minha deixa. Obrigada! >> B.O.

\section{Referências}

ANTUNES, Yaska (Fátima Nunes da Silva). A composição visual no teatro. Anais do $V$ Congresso ABRACE da UFMG - Universidade Federal de Uberlândia - MG, 2008.

APPIA, Adolphe. A Obra de Arte Viva. Lisboa: Arcádia, 1981.

ARNHEIM, Rudolf. Arte \& Percepção Visual - Uma Psicologia da Visão Criadora. Tradução Ivonne Faria. São Paulo: Thomson Learning, 2006.

BACHELARD, Gaston. A Poética do Espaço. São Paulo: Martins Fontes, 2008.

BRACCIALLI, Felipe. Iluminação cênica: possibilidades de um sujeito em cena. Revista Sala Preta, Vol. 15 n. 2, 2015, São Paulo.

BRANDI, Mirella. A linguagem autônoma da luz como arte performativa: a alteração perceptiva através da luz e seu conteúdo narrativo. Revista Sala Preta, Vol. 15 n. 2, 2015, São Paulo.

\footnotetext{
${ }^{13}$ Black Out, significa um corte no fornecimento de energia ou extinção de luzes. Em iluminação cênica é o vazio representado no escuro para simbolizar o corte do pensamento, transição de uma cena para a outra, fim do ato ou simplesmente o fim do espetáculo.
} 
BULFINCH, Thomas. O Livro de Ouro da Mitologia - Histórias de Deuses e Heróis. Rio de Janeiro: Ediouro. 2013.

CALVINO, Ítalo. Seis propostas para o próximo milênio. Trad. Ivo Barroso - São Paulo: Companhia das Letras, 1990

CAMARGO, R. G. Função Estética da Luz. Sorocaba: TCM Comunicação, 2000.

CAMARGO, R. G. Conceito de Iluminação cênica. Projeto SEMINALUZ. Rio de Janeiro: Música \& Tecnologia, 2012.

CAMARGO, R. G. Luz e cena: impactos e trocas. Revista Sala Preta, Vol. 15 n. 2, 2015, São Paulo.

COSTA, Iracy. Interseções performáticas: o conceito de performance em Butler e Schechner. Antropologia da Dança III, Pesquisas do CIRANDA - Círculo Antropológico da Dança / Giselle Guilhon Antunes de Camargo (org.) Florianópolis Insular, 2015.

FORJAZ, C. À Luz da Linguagem: A Iluminação Cênica: Instrumento de Visibilidade à 'Scriptura do Visível' (Primeiro Recorte: do Fogo à Revolução Teatral). 2008. 232 f. Tese (mestrado em artes) - Escola de Comunicação e Artes, Universidade de São Paulo, São Paulo, 2008.

FORJAZ, C. À luz da linguagem - um olhar histórico sobre as funções da iluminação cênica. Revista Sala Preta, Vol. 15 n. 2, 2015, São Paulo.

LUCIANI, Nádia M. Design cênico: um caminho possível para a criação da luz e a formação do iluminador. Artigo apresentado no SELUZ - Seminário de lluminação Cênica / A Luz em Cena - V Encontro Catarinense de iluminação Cênica, UDESC Florianópolis - SC, 2013.

MILLÁS, Cláudia. Estudo da função estética e expressiva da luz no espetáculo de dança em palcos italianos. São Paulo: Universidade Estadual de Campinas (UNICAMP), 2007.

PAREYSON, Luigi. Os problemas da estética. São Paulo: Martins Fontes, 2001.

PEDROSA, I. Da cor à cor inexistente. Rio de Janeiro: SENAC, 2009.

QUINET, Antonio. Um Olhar a Mais, ver e ser visto na psicanálise. Rio de Janeiro: Zahar, 2004.

RANGEL, Sônia. Trajeto Criativo. Salvador: Solisluna Editora, 2015. 
RANGEL, Sônia. Olho Desarmado: objeto poético e trajeto criativo. Salvador: Solisluna Editora, 2009.

RANGEL, Sônia. CasaTempo. Salvador: Solisluna Editora, 2005.

ROUBINE, J. J. A Linguagem da Encenação Teatral. RJ: Ed. Zahar. 1998.

SAMPAIO, Flaviana Xavier Antunes. A dança contemporânea em foco: A iluminação como co-autora da cena. 143f. 2011. Dissertação (Mestrado) - Escola de Dança, Universidade Federal da Bahia, Salvador, 2011.

TUDELLA, Eduardo. Design, cena e luz: anotações. Cadernos de Luz - http://www. spescoladeteatro.org.br/cadernodeluz/. SP, 2012.

VILELA, Caetano. Dramaturgia da luz, um conceito operístico. Cadernos de Luz http://www.spescoladeteatro.org.br/cadernodeluz/ . SP, 2012.

Recebido em: 20/12/2017

Aprovado em: 14/03/2018 